
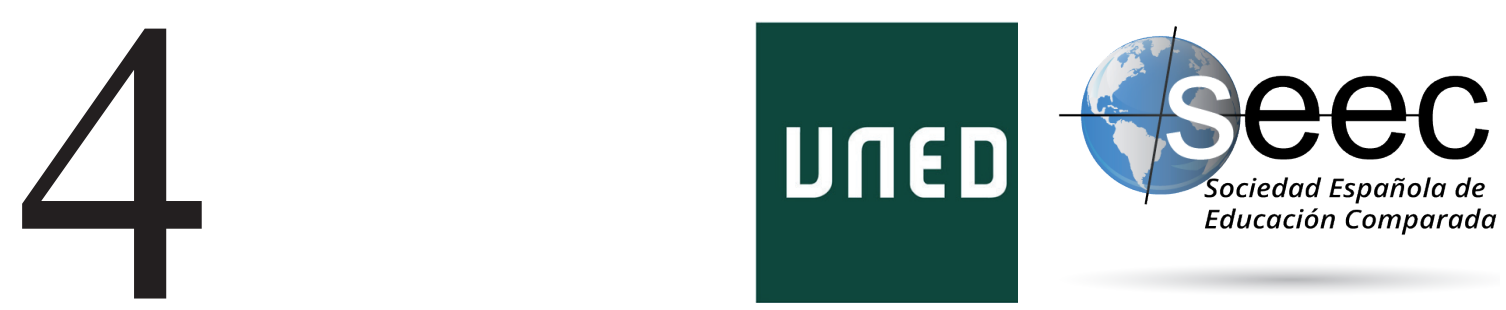

\title{
Dos apuestas por redefinir las funciones del Estado respecto al trabajo magisterial: reformas educativas recientes en México y Ecuador
}

\author{
Two strategies towards a change in public \\ teachers ' labour regulations: recent educative \\ reforms in México and Ecuador
}

\section{Rosa García-Chediak*}

DOI: $10.5944 /$ reec.29.2017.17573

\section{Recibido: 21 de noviembre de 2016 Aceptado: 7 de febrero de 2017}

\footnotetext{
* Rosa García-Chediak: Becaria Postodoctoral DGPA/UNAM Centro de Estudios Latinoamericanos. México. Doctora en Procesos Políticos Contemporáneos por la Universidad de Santiago de Compostela (España), con una tesis sobre los cambios estructurales de la sociedad moderna, su influencia en las instituciones políticas, y la expresión particular de este proceso en la sociedad cubana. Actualmente desarrolla un proyecto de investigación sobre la movimientos sociales en México y Ecuador, en concreto, su impacto sobre diferentes políticas públicas. Ha impartido docencia a nivel de grado y posgrado en diversas universidades. Sus últimas publicaciones son: «Apuntes sobre la génesis del actual sistema educativo español y los fundamentos de sus transformaciones» (2015), «Una aproximación crítica a la educación media superior en Cuba, en el contexto de las sociedades iberoamericanas del siglo XXI» (2014) y «Politización virtual de los jóvenes y ampliación de la esfera pública: una mirada a Cuba dentro del contexto Iberoamericano» (2014) Datos de contacto: E-mail: rosa.garche@gmail.com
} 


\title{
Resumen
}

Las primigenias interrogantes de la Sociología de la Educación sobre las funciones del Estado, han sido revitalizadas por la era global. El presente artículo, desestima que la reducción de las funciones estatales opere como la única e inevitable tendencia. Por el contrario, se sostiene la tesis de una reorientación de las funciones del Estado siempre mediada por orientaciones políticas. A fin de demostrarlo, se analiza cómo afectan a las condiciones laborales de los docentes las últimas reformas educativas emprendidas por México y Ecuador, ambas de carácter profesionalizante. En esta esfera se muestra con claridad la naturaleza de un nuevo intervencionismo, capaz de coexistir con la desregulación (pérdida de derechos) o la subregulación (insuficiente protección) del trabajo de los maestros. Gracias al tiempo transcurrido desde la promulgación legal de sendas reformas, el análisis pone de manifiesto los desfases entre los términos en que se definieron, y cómo se implementan. Se reivindica así el carácter procesual de la refuncionalización, y el papel activo que tienen las distintas fuerzas implicadas en su desarrollo.

Palabras clave: reformas educativas; refuncionalización; profesionalización docente; México y Ecuador

\begin{abstract}
The early questions of the sociology of education about the State roles have been revitalized by the global age. This article dismisses that the reduction of state functions operates as the only and inescapable trend. On the contrary, this paper postulates the thesis of a reorientation on State functions, always directed by political imperatives. To this end, it is analyzed how the last educational reforms undertaken by Mexico and Ecuador -both of a professionalizing sign- affect the working conditions of teachers. In order to this end, we use methodologies of multiple case study. In this area, is clearly shown the nature of a new interventionism, mixed with deregulation (loss of rights) or subregulation (insufficient protection) of teachers' work. Due to the time gap since the legal enactment of these reforms, ant their current implementation, the analysis reveals differences between the definition terms and their practical verification. Thus, is confirmed the refunctionalization as a process in which different forces have active roles.
\end{abstract}

Key Words: educational reforms; refunctionalization; teachers' professionation; México and Ecuador 


\section{Otra vuelta de rosca al debate sobre el funcionalismo de la Sociología de la Educación}

En buena medida, la historia de la Sociología de la Educación ha estado entrampada en el debate sobre el funcionalismo (Martín-Criado 2013), corriente que fundó la disciplina al preguntarse cómo tributa el hecho educativo a la reproducción del sistema social. Aquella interrogante del siglo XIX, era consustancial a la ampliación del acceso a la educación, en la cual los Estados habían tenido que implicarse. Hoy en día, esta continúa siendo una pregunta inevitable, puesto que la participación del Estado en la educación se ha demostrado creciente, y en algunos puntos irreversible, lo cual no es óbice para preguntarse cómo cambian estas funciones.

Durante los años 8os América Latina vivió una particular reedición del debate sobre las funciones del Estado. Por entonces se operaron considerables recortes en los presupuestos nacionales que fueron interpretadas de forma simple y llana como la reducción del Estado, adoptándose el concepto de Estado de mínimos. No obstante, desde una perspectiva más dilatada en el tiempo, la imagen devuelta no termina de calzar con los vaticinios minimizadores. A pesar de ello, es innegable que la presencia estatal ha cambiado. Por estas razones, en este artículo se prefiere utilizar el concepto de refuncionalización, según el cual los instrumentos estatales no desaparecen sino adquieren nuevas funciones en consonancia con los requerimientos del proceso de globalización (Mercado, 2005). En otras palabras, se pretende analizar la reorientación de las funciones estatales, ostensible en la regulación de las condiciones laborales avanzada por las reformas educativas recientes de México y Ecuador. Las reestructuraciones funcionales son indisociables de los reajustes de fuerzas en cada país, factores que complementa la explicación sobre por qué las políticas educativas no son homogéneas, a pesar de existir orientaciones globales y nuevos mecanismos de influencia sobre los Estados (Dale, 2007)

Es útil rememorar que el crecimiento de la cobertura educativa conllevó un intervencionismo estatal caracterizado por una clara apuesta presupuestaria, centralización, expansión burocrática, y, finalmente, sólidos pactos con los sindicatos del ramo. En particular para América Latina, Guillermina Tiramonti (2001) señala que los sindicatos fueron "protagonistas del proceso de institucionalización de los sistemas educativos», y así se incorporaron a la «trama del poder». Estos nexos llegaron a desbordar la simple transferencia de prerrogativas a cambio de convenientes apoyos electorales, dirimiéndose también en este terreno cuestiones cardinales para el funcionamiento del sistema educativo, como los mecanismos de acceso y promoción del personal educativo. Justamente las reformas que aquí examinaremos destacan por la intención de alterar tales vínculos. A lo largo del artículo se intentará demostrar que esta pugna pone en marcha el proceso de refuncionalización, en el que entremezcla intervencionismo, desregulación y subregulación. Esta amalgama si bien se centra en el sistema público, tiene igualmente repercusiones en la enseñanza privada.

A propósito de la transformación que se va abriendo paso en los 80 , es preciso mencionar el énfasis en la calidad educativa, promovido por agencias internacionales como la OECD (1991). Esta nueva preocupación surge impregnada de claroscuros, ${ }^{1}$ y entre sus

1 Cómo se ha reivindicado, la atención a la calidad expresó al menos en parte la intención de subvertir los déficits de aprovechamiento escolar que había traído la ampliación de la cobertura, o de reducir el despilfarro de recursos (Reimers, 2000), pero también se llama la atención a su uso como cuartada para suplantar las políticas universalistas tendentes a la equidad (Sosa, 2012). 
implicaciones directas estuvo la proliferación de evaluaciones estandarizadas, orientadas a realizar comparaciones internacionales. Con el tiempo no sólo los aprendizajes, sino el sistema educativo en su conjunto fue objeto de evaluación, incluyendo sus «recursos humanos». La conjunción de la calidad con los métodos evaluativos, empujó a la docencia a abandonar la condición de empleo para transitar hacia el estatus de profesión.

La tendencia a la profesionalización de la labor docente, implica múltiples supuestos en polémica (Sánchez, 2004:32-48; Feldfeber, 2007). Uno de sus elementos centrales es atribuir a la actividad docente conocimientos y habilidades específicas sujetos constante actualización, y por ende, evaluación. Correlativo a esto, es la implementación de un sistema de movilidad y retribución salarial en función de los resultados de desempeño, donde la antigüedad en funciones pierde su tradicional centralidad. A partir de los efectos de este tipo de incentivos en reformas previas de la educación superior, se considera que las mismas tienden a diferenciar y sobre todo «individualizar» las trayectorias de los maestros, en detrimento de su identificación como colectivo y de las formas de trabajo colegiado (Bensusán y Tapia, 2014:100).

En América Latina, las apuestas por la profesionalización comenzaron en los $90 \mathrm{~s}$ (Banco Mundial, 1996; CEPAL/UNESCO, 1992), pero su debate se intensificó a inicios del presente siglo, cuando diversos gobiernos incorporaron el tema a sus agendas (Tenti, 2004; Murillo, 2007). Es de resaltar que la polémica ha sido mayor en aquellos contextos -como México y Ecuador-, donde no se había dado una burocratización de los empleados públicos del sector educativo, en el sentido de organizar un sistema de reglas objetivas a partir de las cuales reconocer el mérito y la capacidad de desempeñar de determinadas funciones como los criterios efectivos de acceso y promoción a un cargo público. La solución burocrática había pretendido limitar las influencias políticas de diversos actores en la asignación de empleos (gobiernos, partidos, etc.), para lo cual era esencial la estabilidad laboral. En contraste, las reformas profesionalizantes hoy en boga, si bien reivindican la acreditación de conocimientos específicos, condicionan la permanencia en el cargo a la demostración recurrente de competencias. Tanto por limitar las interferencias del sindicato en la gestión de los recursos humanos, como por sus afectaciones sobre derechos laborales previos, las reformas profesionalizantes han enfrentado gran resistencia gremial y, en general, del cuerpo docente. El presente artículo examina las dimensiones que permiten calificar de profesionalizantes a las reformas educativas recientes de México y Ecuador, en el entendido de que esta línea de análisis es donde se concentra el cambio de las funciones estatales respecto al trabajo magisterial.

Desde el punto de vista metodológico, el presente artículo se inscribe en una perspectiva comparativa de estudio de casos múltiples. Para ello, se apoya en una reconstrucción de los contextos particulares de ambos países, a partir de lo cual se avanza mediante las posibilidades de comparación que ofrecen los marcos normativos de ambas reformas, sus últimos ajustes, así como los documentos oficiales que precisan aspectos poco claros de la legislación. Finalmente, en tanto la implementación de las reformas y los conflictos subyacentes son temas de extrema actualidad, se apela a técnicas de revisión hemerográfica para detallarlos. 


\section{Las distintas caras de la reforma educativa mexicana}

Hacia finales de 2012 se estrenaría un nuevo gobierno en México, decidido a impulsar reformas en distintos ámbitos. La educación no escaparía a la vorágine, y a lo largo de 2013 se promulgarían cambios constitucionales (artículos 3 y 73), modificaciones a la Ley General de Educación (LGE) vigente y dos nuevas leyes, la Ley General de Servicio Profesional Docente (LGSPD) y la Ley del Instituto Nacional para la Evaluación de la Educación. Entre las múltiples dificultades que aquejaban a la enseñanza obligatoria, ${ }^{2}$ las medidas se centraron en el problema de la «calidad». En términos discursivos, el gobierno adoptó la consigna de «recuperar la rectoría del sistema educativo nacional», incluyéndola en el Pacto por México. ${ }^{3}$ Como se detallará a continuación el grueso de los cambios introducidos se orientaban a la educación pública, y específicamente a trasladar nuevos imperativos al personal educativo, en un intervencionismo que llegaría asomarse a los umbrales de la enseñanza privada. No obstante, a diferencia de la agenda intervencionista clásica, en este caso la reforma supondría retrocesos en cuanto a la protección laboral, al tiempo que mantendría subreguladas otras áreas del trabajo docente.

\subsection{Las contradicciones del nuevo intervencionismo mexicano}

El uso del concepto de «rectoría» en la reforma educativa de México, anunciaba ante todo un nuevo intervencionismo del Estado, ${ }^{4}$ cuya razón de ser implicó un profundo reajuste en sus relaciones con los principales sindicatos del sector, el Sindicato Nacional de Trabajadores de la Educación (SNTE) y la Coordinadora Nacional de Trabajadores de la Educación (CNTE), una organización escindida del primero. Esta orientación se presentaba como respuesta al amplio reclamo social en pos de subvertir la notable influencia del sindicalismo magisterial en las políticas educativas. ${ }^{5}$ La pugna se ha centrado en afianzar la regencia del Estado sobre la regulación del trabajo docente, promoviendo un nuevo sistema que considera a los maestros no como meros empleados públicos sino ante todo como profesionales. Al acentuarse la profesionalización, se colocó en un primerísimo plano los procedimientos evaluativos. La centralidad del concepto de evaluación es donde se manifiesta con mayor claridad el intervencionismo de nuevo cuño que distingue a la reforma educativa mexicana.

La evaluación se demuestra emblemática de los ánimos de rectoría desde la afirmación de su carácter obligatorio en el artículo $3^{\text {ro }}$ constitucional. El texto le confiere a

$2 \quad$ La reforma no abarcaría el nivel preescolar.

3 Iniciativa desarrollada por el presidente Enrique Peña Nieto mientras se efectuaba la transición gubernamental en 2012, a fin de articular consensos entre las cúpulas de los partidos mayoritarios (PRI, PAN y PRD) e impulsar así un conjunto de reformas.

4 Este significado difiere del primigenio concepto de «rectoría», introducido en la Constitución en 1982 para limitar las funciones del Estado en determinadas áreas del desarrollo económico, y reivindicar la necesidad de coordinación con el sector privado pero también el sector social - los sindicatos- (Art.25 de la Constitución)

$5 \quad$ El peso del sindicalismo magisterial en la gestión del sistema educativo mexicano es un hecho documentado (Ornelas, 2008 y 2012; Arnaut, 2010; Fernández-Martínez, 2012) y también un sentimiento extendido entre la población. Estas percepciones han sido utilizadas por el grupo de presión Mexicanos Primeros, productor del conocido documental «De panzazo» que enfatiza en una visión negativa de los maestros mexicanos. A este grupo se le atribuyen vínculos con figuras relevantes del empresariado mexicano (Hernández, 2010). 
los resultados de la evaluación un carácter determinante para el ingreso, la promoción (obtener más horas, estímulos económicos o cargos de supervisión y dirección), el reconocimiento (acceder a cargos de tutor o asesor técnico pedagógico) o la permanencia (mantenerse en la misma función) dentro del servicio docente de educación básica y media superior. Lo anterior, se hizo acompañar por una manera diferente de implementar los procesos evaluativos.

La primera novedad de los actuales procedimientos evaluativos es la preponderancia que adquiere el Instituto Nacional para la Evaluación de la Educación (INEE), sobre quién recae la competencia de emitir los lineamientos a que se sujetarán las Autoridades Educativas -federales y locales- para aplicar las evaluaciones (Art. 29 de la LGE y Art. 28 de la Ley del INEE). Por lo demás, las modificaciones constitucionales definieron al INEE como «organismo público autónomo», con el fin de garantizarle «la independencia necesaria para asegurar la confianza en los resultados de las evaluaciones». ${ }^{6}$ De esta manera, se refuerza la pretensión de hacer del INEE un ente cuya objetividad descanse en el saber de sus especialistas, capaces de aportar soluciones técnicas pero sobre todo libres de las influencias políticas de la SEP, los empresarios, y muy especialmente, de los sindicatos.

Con la redefinición del INEE, se introdujo un contrapeso al control de la administración educativa por fuerzas de la SNTE y CNTE, al excluirles de participar en la elaboración de los lineamientos de evaluación. Al respecto, el artículo 28 de la Ley del INEE siquiera les considera en el papel de «observadores» de las evaluaciones, aludiendo sólo a las llamadas organizaciones de la sociedad civil (OSCs). A mayores, si bien la Ley prevé la participación del «sector social» en el Consejo Social Consultivo del INEE, en su posterior Estatuto Orgánico, sólo se precisan los requisitos de participación para las OSCs, quienes han sido de hecho las únicas representadas en este órgano, además de la patronal COPARMEX. En esto se trasluce la nueva influencia que adquieren las OSC's y cámaras empresariales en el rumbo de las políticas educativas, otro de los signos políticos del actual proceso reformador. ${ }^{7}$ En todo caso, se llama la atención sobre las funciones consultivas -no vinculantes- del citado Consejo. Por su parte, la LGSPD reducirían aún más la influencia de los sindicatos. En primer lugar dejó sin efecto las comisiones mixtas SEP-SNTE, que determinaban el ingreso, promoción y reconocimiento de los maestros, siendo la SEP quien asume la determinación de los estándares para cada uno de estos movimientos, que quedan mediados por las evaluaciones elaboradas según los lineamientos del INEE. La LGSPD sin embargo sí menciona a los sindicatos como «observadores» no meramente de los concursos sino de «los procesos» de promoción a cargos con funciones de supervisión y dirección (Art. 33)

Es importante acotar que en la práctica y a pesar de su autonomía, el desempeño del INEE ha tendido a alinearse con la política de la SEP. Esta conjunción no se explica sólo porque la SEP haya dado pasos en el sentido de regularizar el proceso de asignación de las plazas docentes y depurar el diagnóstico de las necesidades de formación de los maestros, procesos viciados por las intervenciones sindicales. Suscribir tales intenciones, no obligaba al INEE a asumir de forma implícita las consecuencias laborales de la evaluación, a pesar de existir indicios de que la Directiva del INEE preferiría un enfoque

$6 \quad$ Ver Resumen Ejecutivo de la Reforma Educativa. Disponible desde internet en http://www.gob. $\mathrm{mx} / \mathrm{cms} /$ uploads/attachment/file/2924/Resumen_Ejecutivo_de_la_Reforma_Educativa.pdf con acceso 18-08-2016

$7 \quad$ Han llamado la atención sobre este aspecto investigadores como Manuel Gil Antón, Hugo Aboites, Raquel Sosa, y Luis Hernández Navarro, aunque es un asunto todavía pendiente de mayor investigación. 
más flexible y formativo. ${ }^{8}$ La línea política que ha terminado permeando el trabajo del INEE tiene disímiles condicionantes, entre las que destacamos el modo de designación de los integrantes de su Junta Directiva, ${ }^{9}$ y las escasas posibilidades de intercambios con los docentes que prevé su diseño institucional. ${ }^{10}$ Puntualizando, en el tándem SEP-INEE afloran de forma nítida una cualidad del nuevo intervencionismo estatal, la cual consiste en apelar a un ente legitimado por el saber experto y la «autonomía», para impulsar evaluaciones que acrediten el nivel profesional de los docentes, y - como veremos-subordinar a ello sus derechos laborales. A fin de redondear la cualidad intervencionista del INEE, es útil corroborar el aumento exponencial del financiamiento público que se le destina. ${ }^{11}$

Llegados a este punto, es importante destacar que la actual reforma educativa que se implementa en México, si bien supone para el Estado un nuevo intervencionismo, le conmina de igual modo a prácticas de desregulación laboral. A propósito se ha llegado a valorar que la reforma educativa introduce un régimen laboral específico para el magisterio público (Ramírez, 2013:123; Alcalde, 2014:115-116). En última instancia, la cualidad distintiva de este ordenamiento se define por una sustantiva disolución de la estabilidad laboral que distinguía a los maestros. A estos fines es imprescindible analizar la LGSPD que si bien no aumentó significativamente el número de causales de despido -homologando las vigentes para el resto del sector público-, sí concretó el imperativo constitucional de condicionar la permanencia a la evaluación.

A fin de ilustrar la tesis anterior, es conveniente comenzar por las vías de acceso al servicio docente. La instauración de concursos representó avances innegables (especialmente el de interrumpir la venta o herencia de plazas), pero se conjugó con un condicionamiento perentorio a la permanencia en el empleo. Según el artículo 22 de la LGSPD, quienes resulten ganadores de una plaza mediante la superación del respectivo concurso, obtendrán el nombramiento definitivo a los 6 meses. Sin embargo, esta «definitividad» podrá darse por terminada a los dos años, si el docente no atendiera a los programas de capacitación, no asistiera a la evaluación diagnóstica o resultara insuficientemente evaluado en la misma. A mayores, son reforzadas las condiciones punitivas del despido al pautar que este se efectúe «sin responsabilidad para la Autoridad Educativa o para el Organismo Descentralizado», es decir, sin liquidación y afirmando por anticipado su carácter procedente. De esta forma, se suprime el componente de inamovilidad que estaba asociado a un nombramiento definitivo.

Tampoco se encuentra al margen riesgos el personal de más experiencia o con funciones de mayor rango. Así, los artículos 52 y 69 de la LGSPD pautan la obligatoriedad de someterse a evaluaciones de desempeño periódicas a los docentes, directores

8 Cfr. Opiniones de Sylvia Schmelkes (2014) y Gilberto Guevara Niebla (2016), presidenta y Consejero de la Junta de Gobierno del INEE.

9 Según la ley que regula al INEE, los integrantes de la Junta directiva son propuestos el Ejecutivo Federal y ratificados por el SENADO donde los partidos firmantes del Pacto por México determinan las mayorías.

10 La ley del INEE no estipula que participación alguna de los docentes en la definición de los «parámetros e indicadores» a partir de los cuales serán evaluados. A pesar de esto, el INEE ha intentado por su cuenta y riesgo incorporar los puntos de vista de los docentes en la elaboración del modelo de evaluación que regirá para 2017.

11 Según la Información de Gestión Administrativa publicada en la web institucional del INEE (http:// www.inee.edu.mx/index.php/micrositio-transparencia/502-micrositio-transparencia/informacion-sobreel-presupuesto/1646-fraccion-ix con acceso 25-06-2016) el presupuesto para 2016 fue de $1060 \mathrm{Mdp}$, con un crecimiento del $261 \%$ respecto al aprobado para 2013. 
y supervisores..$^{12}$ De hecho, en el caso mexicano la participación de los docentes en la primera evaluación de desempeño es indisociable del miedo generado por las advertencias de despido cursadas por la SEP, teniendo nula incidencia los incentivos económicos anunciados. ${ }^{13}$ Para los docentes que distribuyen su jornada entre diversas asignaturas, las exigencias se acrecientan pues la SEP defiende que es obligatoria la evaluación en todas las disciplinas (Poy, 4 de marzo de 2016). Para más señas, la LGSPD contempla ocho obligaciones que de ser incumplidas pueden originar la finalización de nombramientos definitivos (Art. 69), a las que se adicionan la prohibición de incumplir con la asistencia a sus labores por más de tres días consecutivos o discontinuos en un periodo de treinta días naturales (Art.76), y la completamente inédita de reprobar en tres ocasiones de las evaluaciones de desempeño (Art. 53). La radicalidad del Artículo 53, se intentó matizar pautando la reubicación en puestos administrativos o programas de retiro, pero sólo para quienes hubiesen obtenido su nombramiento antes de la promulgación de la LGSPD (disposición Transitoria Octava)

El sustancial vaciamiento de la estabilidad laboral de los docentes públicos, se amarra en un modo simplificado de tramitar la terminación de un nombramiento, es decir, su despido. Se ha argumentado que la modificación del Artículo 3 constitucional sustrajo a los trabajadores de la educación de la protección que brinda el Artículo 123 y la Ley Federal de Trabajadores al Servicio del Estado, a los empleados públicos (Fuentes, 2013). Así, mediante el cambio constitucional y la LGSDP (artículos 74 y 76), se avala que la finalización de un nombramiento acontezca no sólo sin derecho a percibir indemnización, sino también eliminando el requisito de que exista «resolución previa del Tribunal Federal de Conciliación y Arbitraje o sus equivalentes en las entidades federativas», esto es, de un órgano autónomo de justicia laboral - resabio de la organización corporativa del Estado- en el cual el trabajador puede solicitar representación sindical y donde además interviene un magistrado designado por los sindicatos, dada su conformación tripartita. En lugar del procedimiento anterior - por lo general tardado- la LGSPD instaura un trámite ágil, donde en el plazo de veinte días hábiles la administración notifica al trabajador, este presenta pruebas en su defensa y la misma instancia administrativa emite la resolución definitiva, sin que se contemplen garantías suficientes para calificar el trámite como un sumario administrativo (Art 75.) A partir de la ampliación de las causales de despido, naturalmente se reduce la efectividad de los mecanismos de impugnación (Art. 80 y 83). Aunque desde octubre de 2013 se pusieron en marcha tentativas de revertir estas disposiciones de la reforma mediante recursos de amparo que alegaban su carácter inconstitucional, estas se demostraron infructuosas a mediados de 2015, cuando la Suprema Corte de Justicia Nacional (SCJN) confirió plena validez a las medidas de separación del cargo después de tres faltas consecutivas, de reprobar en tres ocasiones las evaluaciones de desempeño o finalmente de ausencia injustificada a las

12 El INEE ha determinado que las evaluaciones de desempeño se realizarán cada dos años para la totalidad del personal educativo, salvo quienes obtengan calificaciones insuficientes que deberán ser evaluados al año siguiente.

13 La más notoria de ellas fue realizada por el Secretario de Educación Pública Aurelio Nuño el 15 de octubre de 2015 (Hernández, 15 de octubre de 2015). Por otra parte, el monto de los incentivos salariales asignados a los profesores con mejores niveles de desempeño, no sería dado a conocer oficialmente hasta el 16 de mayo de 2016 -Comunicado 219 de la SEP- esto es cerca de 5 meses después de finalizada la primera ronda de evaluaciones. 
evaluaciones. ${ }^{14}$ Es importante precisar que estos nuevos dispositivos no constituyen una amenaza latente, sino que han dado paso a millares de despidos. ${ }^{15}$

Con base en los argumentos anteriores, se observa un retraimiento de las funciones de protección laboral que había desempeñado el Estado mexicano, al cual se califica como desregulación. Existen opiniones de que era imprescindible refrendar legal e incluso constitucionalmente este tipo de poder determinante de las evaluaciones, como único modo de contener el poder enquistado del SNTE (Paoli, 2013:174). En realidad, otras experiencias recientes cuestionan tal «necesidad», en especial la reforma de la Educación Superior realizada en el país durante los 8os, en la cual se instauraron los requisitos de un concurso de oposición para acceder a una plaza y una evaluación académica única para acceder a la estabilidad laboral (definitividad), mientras las mediciones de desempeño se vincularon a incentivos económicos. Debe considerarse además que el poder sindical se mantiene a resguardo en otros recovecos de la administración educativa, entre ellos el control de algunas Secretarías de Educación estatales (Del Valle, 2015) pero sobre todo de los mandos medios (supervisores escolares, jefes de área y directores de escuelas). En realidad, el saldo de esta avanzada sobre los sindicatos si bien ha debilitado su presencia institucional en la administración del sistema educativo, se inclina en mayor medida hacia un acrecentado control de la SEP sobre el personal educativo.

$\mathrm{El}$ peso de las disposiciones laborales dentro de la reforma ha determinado que las iniciativas de modificar su corpus normativo, tomen a la LGSPD como primer objetivo. ${ }^{16}$ Por otra parte, los enormes conflictos derivados del contenido laboral de la reforma educativa, ponen en cuestión la idea de que estos cambios eran una antesala para otros. Un mal comienzo fue el deficiente tratamiento conferido al financiamiento educativo y su federalización (Fernández-Martínez, 2014). Mucho más improbable parece que en lo que resta de sexenio se pueda avanzar con solidez en un nuevo modelo educativo, cuyo debate público fue aplazado por la SEP hasta la segunda mitad de 2016. Queda también por verificar si el fuerte énfasis en los aspectos negativos, alcanzará a ser equilibrado en la balanza coste-beneficio de los docentes, por los estímulos positivos, tales como: incrementos salariales, el aumento de número de horas, los ascensos verticales, los mecanismos de apoyo al trabajo docente, las opciones gratuitas de superación profesional contenidas en la reciente Estrategia Nacional de Formación Continua, o el plan de fortalecimiento de la formación inicial de los docentes y del Sistema de Normales Públicas.

Es interesante notar que el intervencionismo de la presente reforma no sólo coexistió con la desregulación en el plano laboral, sino también con una insuficiente regulación de distintas áreas del trabajo docente. En este sentido, se ha apuntado que la reforma mexicana no pauta la distribución de la jornada laboral entre tareas frente a grupo y otro tipo de actividades pedagógicas; no promueve formas de trabajo colegiado; no se pronuncia sobre abatir la contratación temporal-profesores interinos, docentes contratados por obra o tiempo determinado-y, finalmente, tampoco especifica cómo se atenderá la desigualdad de condiciones o «contextos locales» (De Ibarrola, 2014:90-92). Esta

14 Un análisis detallado de los argumentos de los magistrados de la SCJN para fundamentar estos y otros fallos a los amparos interpuestos en (Marín, 2015a, 2015b)

$15 \quad$ El mayor número de despidos involucró a 3 mil 36o docentes que no se habían presentado a las evaluaciones de desempeño en 2015 (SEP, 1 de marzo de 2016)

16 Revisar el acuerdo entre representantes de la CNTE y senadores del PRD, PT y Morena para crear un frente parlamentario, alcanzado el 11 de julio de 2016 (Mercado y Brito, 11 de julio de 016), o la propuesta de modificaciones a la legislación secundaria que miembros del PRD sugirieron a militantes de la CNTE encaminar como iniciativa ciudadana, el pasado 24 de agosto de 2016. (Rosas, 24 de agosto de 2016) 
última condición parece ser a ser incorporada parcialmente, a partir de la redefinición del modelo de evaluación de desempeño anunciada por el INEE para el 2017.

\subsection{Las derivas de la reforma mexicana sobre la enseñanza privada}

Hasta aquí, se ha hecho evidente, el centro de las reformas atañe al sector público. Sin embargo, otra serie de cambios predisponen también una mayor injerencia del Estado en la enseñanza privada. Esta arista nos permite apreciar como al interior de la reforma actúan imperativos de control burocrático con cierta independencia respecto de las motivaciones políticas. Al mismo tiempo, se observará que la reforma no tiene mayores implicaciones sobre la realidad laboral de estos docentes, que se mantienen subreguladas en el escueto marco de las protecciones laborales previas.

Siguiendo la tesis de que la actual reforma educativa supone grados mayores de intervencionismo estatal sobre la enseñanza privada, esta se ampara en la precisión incorporada al artículo 3ro constitucional sobre la «calidad en la educación obligatoria», la cual abarca a las escuelas particulares. En cuanto a la legislación secundaria, el cariz intervencionista se revela en la obligación de que la SEP evalúe el desempeño de los maestros de planteles privados según los mismos lineamientos que determine en INEE para instituciones públicas (Artículo 21 de la LGE). ${ }^{17}$ De conseguir resultados satisfactorios, los docentes obtendrían un certificado que los avale, de lo contrario se le ofrecerán cursos de capacitación o programas de regularización, sin mencionar si estos serán obligatorios. Aunque no solventar con éxito la evaluación, no se impone aquí como causal de despido ni afecta el reconocimiento de validez oficial del centro, sí se mandata que deberán hacerse públicos los nombres de los docentes que hayan cumplido con esos requisitos (Artículo 56), apelando con ello a la sanción indirecta de los padres de familia. A pesar de estas prevenciones, a la fecha no se ha realizado ninguna evaluación de esta naturaleza, y al menos hasta junio de 2016 el INEE sostenía en el apartado de preguntas frecuentes de su web institucional que «la evaluación del desempeño docente sólo será para las escuelas públicas» ${ }^{18}$

En paralelo con la avanzada intervencionista prevista para los docentes de las privadas, es llamativo que el Estado no haya tomado medida alguna para reducir las diferencias en las condiciones laborales que distinguen a estos trabajadores respecto de quienes laboran en el sector público, entre las que destacamos su menor capacidad negociadora - y por tanto de obtener mejores salarios--, o su mayor incertidumbre laboral (Hernández, Llamas y Garro; 2012:319). Al menos sobre la estabilidad laboral los datos del Censo de Escuelas, Maestros y Alumnos de la Educación Básica (CEMABE) publicado en 2013 reflejaban que el 35,2 \% de los docentes de las privadas estaban contratados por honorarios, mientras que un 7,6 \% eran trabajadores eventuales. Como resulta obvio, la incidencia de las formas de contratación temporal se traduce igualmente en un acceso limitado a las prestaciones de ley y a la cobertura en seguridad social. La no implementación de las evaluaciones de desempeño en el ámbito privado, limita que se pudieran

17 Hasta la presente reforma educativa, la adecuada preparación profesional del personal directivo y de las escuelas privadas se controlaba mediante las inspecciones a los planteles, donde mayormente se comprobaba que estuvieran en posesión de las cédulas profesionales o documentos académicos, según diversos acuerdos secretariales relacionados con la autorización para impartir educación (254,255,276 y 357)

18 Esta información se puede consultar su versión caché con fecha del 12 de junio de 2016 en http://webcache.googleusercontent.com/search?q=cache:guISMTUTsagJ:www.inee.edu.mx/index.php/ proyectos/524-reforma-educativa/preguntas-frecuentes/1622-preguntas-frecuentes $+\& c d=1 \& h l=e s \& c t=c l n$ $\mathrm{k} \& \mathrm{gl}=\mathrm{mx}$ con acceso $1-09-2016$ 
utilizar sus resultados para incentivar por ejemplo la contratación a tiempo completo, u otros beneficios laborales.

A modo de síntesis, el intervencionismo, la desregulación y la sub-regulación, son distintas caras del concepto de «rectoría» que bien expresan la refuncionalización que se opera en la reforma educativa mexicana. Como se examinó, el proceso se ha caracterizado por una nueva avanzada intervencionista, centrada en distintos mecanismos de evaluación del personal docente. En paralelo, la reforma también ha flexibilizado disposiciones laborales que protegían al magisterio del sector público, desdibujando los contornos de su anterior estabilidad laboral. A pesar de primar los vectores del intervencionismo y la desregulación en el sector público, se evidencian igualmente áreas de subregulación. Por último, es interesante notar que el intervencionismo abarca sólo tangencialmente al ámbito de la enseñanza privada, dejando a sus trabajadores en el mismo entorno de derechos garantizados de modo deficitario.

\section{Ecuador, una apuesta intervencionista entre el querer y el poder}

Desde el nuevo gobierno instaurado en 2006, el sistema educativo ecuatoriano ha experimentado cambios significativos en todos sus niveles y modalidades, incluida la educación superior. En aras de propiciar el contraste con México, se ha delimitado como campo de análisis la educación obligatoria. ${ }^{19}$ En este marco, la expresión más elaborada de las transformaciones llegaría con la promulgación de una nueva Constitución en 2008, la Ley Orgánica de Educación Intercultural (LOEI) de 2011, su respectivo Reglamento General de 2012, más las reformas de 2015 a las dos últimas normativas. Como se detallará, este cuerpo legal resulta especialmente novedoso en las distinciones que introduce en la regulación del trabajo del personal educativo.

\subsection{El predominante intervencionismo de la reforma ecuatoriana, viejos y nuevos métodos}

Con la proclamación de la Constitución de 2008, se definieron un número importante de exigencias para la educación y la conducción estatal de la misma, resumidas con la siguiente fórmula:

«El Estado ejercerá la rectoría del sistema a través de la autoridad educativa nacional, que formulará la política nacional de educación; asimismo regulará y controlará las actividades relacionadas con la educación, así como el funcionamiento de las entidades del Sistema» (Art. 344).

Le envergadura del concepto de «rectoría» se profundizaba al enumerarse las políticas de educación entre los ámbitos de competencia exclusiva del gobierno central (art. 261), prefigurando un mayor intervencionismo. Sin embargo, en Ecuador, se incluyeron elementos del repertorio intervencionista clásico «[...] fortalecer la educación pública, ampliación de la cobertura, la infraestructura física y el equipamiento necesario[...]» y se incorporaron funciones más novedosas como la de «asegurar el mejoramiento permanente de la calidad» (Art. 347). Respecto al problema de la calidad, el texto constitucional

19 En el país ésta comprende a la Educación General Básica y —desde la Constitución de 2008- al Bachillerato, suponiendo 13 años de escolarización continuada. 
apuntó la creación de «una institución pública, con autonomía, de evaluación integral interna y externa» (Art. 346), en un giro semejante al planteado por la reforma mexicana.

En cuanto a la regulación del trabajo docente, el intervencionismo asumió varias tonalidades. Para comenzar, se definió encomienda del Estado el garantizar a los docentes las condiciones idóneas para su trabajo, comenzando por la «estabilidad» (Art. 349). En el mismo artículo, se pautó la necesidad de una ley que regulase la trayectoria profesional, un sistema de evaluación del desempeño y la política salarial. De forma idéntica a lo revisado para México, se abría la brecha para instalar un régimen laboral específico para los profesores. Es de resaltar que se adoptó una designación comprensiva de los docentes, aspecto que permitió que la legislación secundaria incorporara a los maestros de las escuelas privadas. Por lo demás, la Constitución incluye un compromiso explícito de tomar «medidas con el fin de superar la precariedad» y a diseñar políticas adecuadas para «el mejoramiento y regularización de la planta docente» (Disposición Transitoria Decimonovena).

Luego de agudas movilizaciones en 2009 y 2010,${ }^{20}$ debates espaciados a lo largo de tres años y un veto parcial del Presidente, a finales de marzo de 2011, estaba lista para su promulgación la Ley Orgánica de Educación Intercultural (LOEI). En el plano de las relaciones laborales, la ley profundizó el intervencionismo estatal. En este sentido organizó el funcionamiento de la carrera docente, entendida como la trayectoria laboral de los maestros de colegios públicos y fiscomisionales, ${ }^{21}$ de un modo más completo que como hasta el momento la había regulado la anterior Ley de Carrera Docente y Escalafón (LCDE) de 1991 y profundizando las directrices del Decreto 708 de 2007 en cuanto a sustraer estos procesos del control de la Unión Nacional de Educadores (UNE). Atípicamente, el ordenamiento laboral específico para los docentes, fue mejor apreciado que el establecido por la Ley Orgánica de Servicio Público (LOSEP) de 2010 para el resto de los empleados públicos, especialmente en términos salariales.

Los cambios de la LOEI consolidaron la organización por el MINEDUC de un sistema meritocrático para el ingreso y ascenso de los docentes, cargos directivos y diversos funcionarios (Arts. 97-110), con reglas claras para la inscripción de los candidatos, la participación en los certámenes y la asignación de nombramientos en función de los resultados. En el empeño de dar nuevos pasos, la LOEI definió las competencias del Instituto Nacional de Evaluación Educativa (INEVAL) como entidad responsable de diseñar e implementar los concursos de oposición y también de la totalidad de las evaluaciones del sistema educativo ecuatoriano. Para ello se constituía «como entidad de derecho público, con autonomía administrativa, financiera y técnica» (Art. 67). Sin embargo, el diseño institucional del INEVAL es clave para situar como el intervencionismo se alineaba más con las fuerzas que dirigían el Estado, en desmedro del poder sindical. Así, la máxima instancia de decisión dentro del órgano - la Junta Directiva - se conformaría por tres miembros, designados por el titular del Ejecutivo Ecuatoriano, por la Secretaría Nacional de Educación Superior, Ciencia, Tecnología e Innovación; y por la Secretaría Nacional de Planificación y Desarrollo, tras superar concursos de oposición y demostrar

20 En 2009 se produjeron protestas y un Paro Magisterial en septiembre en contra de la evaluación docente obligatoria (El Universo, 7 de octubre de 2009). El 2010 fue un año crítico por las protestas de sindicatos del sector público contra la tramitación de la Ley Orgánica de Servicio Público e incluso una sublevación policial contra el gobierno el 30 de septiembre, sin que se haya aclarado la participación de la UNE en estos eventos.

21 En las escuelas fiscomisionales la administración es privada pero los recursos financieros son parcial o totalmente públicos, estando obligadas a ofrecer sus servicios de forma gratuita. 
sus aptitudes para el cargo. Sin embargo, el otro puesto clave en el funcionamiento del Instituto -el de Director Ejecutivo- sería seleccionado directamente por la Junta Directiva a partir de una terna presentada por el MINEDUC. A mayores, en el INEVAL no se prevén instancias consultivas, ni mucho menos órganos colegiados de decisión con otros actores, mientras sí se especifica la «necesidad de procesos de coordinación con la Autoridad Educativa Nacional» (Art. 68). De hecho, a diferencia del INEE mexicano, reconocido con claridad como autoridad en materia de evaluación educativa, el INEVAL en Ecuador se apega a los estándares de calidad educativa definidos por el MINEDUC para definir los indicadores operativos que finalmente se aplicarán en las evaluaciones. En resumen, el Instituto se constituye en órgano ejecutor -y no rector- de la política evaluativa y -en el orden operativo- su cúpula se hace depender del Poder Ejecutivo. A pesar de su menor autonomía, el INEVAL está facultado para evaluar incluso la gestión de las autoridades educativas (Art. 68), aportando una visión más integral de la función evaluadora.

Puntualizando, en el caso de la reforma ecuatoriana presenciamos similitudes respecto a los cambios legales analizados para México, en tanto la regulación del ingreso y el ascenso laboral de los docentes se hace descansar en certámenes encargados a entes formalmente autónomos, sobre los cuales el Estado -y en este caso particular la Autoridad Educativa - tiene significativas posibilidades de influir. El nuevo esquema ciertamente limita la incidencia de la tramas clientelares bajo el control sindical. La entronización de este tipo de evaluación obligatoria, se conjuga en la ley con prohibiciones que reducen aún más el margen de maniobra de la UNE, detallando como infracciones como la de «ordenar la asistencia del personal docente, administrativo y/o alumnado a actos públicos de proselitismo político de cualquier naturaleza» (Art.132). Sin embargo, la disputa por limitar las interferencias sindicales en la evolución del sistema educativo, no se conjugó con avances en las cláusulas de protección laboral como veremos a continuación.

Antes de avanzar hacia el análisis de la desregulación, conviene apuntar un último aspecto elocuente del intervencionismo de la LOEI. Se trata de la definición de la jornada laboral, aspecto también sujeto a considerable polémica. ${ }^{22}$ A partir de 2011 esta quedó fijada en 40 horas-reloj semanales, de las cuales 30 horas serían frente a clase, de acuerdo con el Reglamento General. El resto del tiempo, se reservaba para «labores educativas fuera de clases» - planificar clases, atender a familiares, corregir exámenes, etc. - pero especificando que estas implicaban la permanencia en el centro educativo. Esta era una exigencia inédita, que el gobierno juzgó coherente con las políticas de ampliación de los nombramientos y de aumentos salariales, condiciones que limitaban la necesidad de recurrir al pluriempleo. La ley reformatoria de 2015 y las consiguientes modificaciones al Reglamento General, limitaron a 6 horas académicas diarias la permanencia en el centro escolar, permitiendo que el resto de tiempo dedicado a otras tareas pedagógicas pudiera realizarse en otros entornos, pero reportando las labores realizadas mediante el programa «Comunidad Educativa en Línea», para lo cual les ha sido entregado un kit tecnológico.

Sobre cómo resultan afectados los derechos laborales de los trabajadores con la reforma educativa en Ecuador, la dimensión más problemática vuelve a ser la estabilidad en el empleo, limitada ahora de forma sui géneris. Es de reconocer que tanto en

22 Muestra de ellos son las manifestaciones convocadas por la UNE en 2011 (La República, 5 de octubre de 2011), así como las advertencias de autoridades del MINEDUC de que los faltistas serían sancionados (PP Digital, 5 de octubre de 2011) 
la Constitución y como en la LOEI prima el espíritu de concebir la estabilidad como un componente central en el servicio docente. Así por ejemplo, para quienes superan los concursos de ingreso y adquieren un nombramiento provisional, la LOEI no impone una evaluación diagnóstica para mantenerse en el servicio y obtener la definitividad, sino las razonables condiciones de aprobar cursos de inducción de dos años y la obtención de una titulación pedagógica para bachilleres o licenciados en otras disciplinas. De hecho, los concursos de ingreso han sido la vía fundamental de asumir el compromiso constitucional de abatir los altos índices de contratación temporal. ${ }^{23}$ Sin embargo, el principio de la estabilidad laboral no resulta siempre garantizado de modo adecuado.

En primer lugar, la LOEI aumentó significativamente el número de prohibiciones, que superan las vigentes para el resto de los servidores públicos, entre ellas quince determinantes de «destitución del cargo». A estas se agrega la de reprobar en sólo dos ocasiones consecutivas las evaluaciones de desempeño (Art. 133, inciso f), para las cuales el INEVAL fijó una frecuencia bianual, salvo para los «evaluados de insuficientes» que tendrían que rendirla al año siguiente. Más problemático que el aumento de las causales de despido, resulta el proceso de tramitación de las destituciones. En este sentido la LOEI establece que este tipo de sanción grave se imponga por la vía de sumario administrativo, contemplando dos posibilidades de impugnación: apelar ante la autoridad educativa del nivel inmediato superior o recurrir ante un Tribunal de lo Contencioso Administrativo. Si bien este procedimiento abreviado estaba en la anterior LCED y es recurrente en las leyes de servicio público de la región, contrasta con otras soluciones por ejemplo del derecho administrativo español donde las sanciones graves conllevan un proceso disciplinario ordinario con mayores garantías legales. Hasta aquí, se podría concluir que el aumento del número de prohibiciones causantes de destitución, deja a los trabajadores más expuestos a enfrentar fallas procesales. ${ }^{24}$ Pero captar la singularidad de la desregulación - en tanto deterioro de la estabilidad laboral previamente garantizada - exige examinar las instancias implicadas.

Según la LOEI, será competencia de las Juntas Distritales de Resolución de Conflictos imponer las medidas disciplinarias más severas, cuyos miembros son nombrados por la autoridad ministerial (Art. 65). De este modo, se sustituyeron a las anteriores Comisiones Regionales y Provinciales de Defensa Profesional, donde sí intervenían los sindicatos con gran capacidad de bloqueo de las sanciones, garantizando de facto la estabilidad laboral. Más allá, se han apuntado otras imperfecciones en el diseño de las Juntas, entre ellas que sus integrantes - al tener otras ocupaciones- no disponen del tiempo pertinente para desarrollar el sumario, ni cuentan con una adecuada composición profesional de abogados y psicólogos (Salazar, 2016:89). La LOEI tampoco determinó jerarquías entre los integrantes de la Junta, aspecto que la reformatoria de 2015 resolvió indicando que serían presididas por el Director Distrital. En este punto específico, se observa que la combinación entre el aumento de las prohibiciones, los procedimientos de sumario, y un diseño insatisfactorio de las Juntas Distritales, podría atentar contra los derechos de los trabajadores. Nuevamente se plantea aquí el dilema de si esta era la única solución

23 Según las declaraciones del ministro del rubro cerca del $90 \%$ de los maestros públicos habían obtenido un nombramiento oficial en abril de 2015 (El Telégrafo, 14 de abril de 2015).

24 Considérese por ejemplo que según el Reglamento de la LOEI el sumariado sólo dispone de dos ocasiones para presentar pruebas en su defensa: una al momento de ser notificado del inicio del sumario (plazo de 3 días naturales) y otra en la etapa de pruebas ( 5 días hábiles en los que también podrá solicitar se practiquen nuevas investigaciones); además se limita a 24 horas de anticipación la convocatoria a audiencia; y finalmente, no se fija el plazo en que la Junta debe resolver el sumario. 
para limitar el control sindical sobre el sistema educativo. En todo caso, cabe aclarar que hasta el momento no se han producido despidos masivos. Quizá más riesgoso para la estabilidad resulte la ampliación del rango de los nombramientos provisionales o incluso la rehabilitación legal de los contratos de servicios ocasionales, que se observa en las reformas de 2015 .

Concretamente en cuanto a la evaluación de desempeño, vale decir que el magisterio ecuatoriano e incluso la UNE terminaron aceptando el nuevo esquema, como lo demuestra el acuerdo alcanzado en octubre de 2009 (Ecuador Inmediato, 7 de octubre de 2009) y la masiva participación en concursos. Tal desenlace fue favorecido por un aumento explícito de las remuneraciones, tanto las que supusieron las categorías de escalafón. ${ }^{25}$ La reciente simplificación de las categorías escalafonarias -reducidas de once a siete por la ley reformatoria de 2015- aumentó la valoración positiva de los mecanismos de ascenso. Asimismo, la regulación por acuerdos ministeriales en 2014 y 2015 de la «recategorización docente» enunciada por la LOEI - una posibilidad excepcional y voluntaria de ascenso acelerado en el escalafón - ha aumentado la legitimidad de las evaluaciones. ${ }^{26}$ Además la variedad de instrumentos evaluativos (incluidos evaluación por pares, observación de clases, y cuestionarios llenados por estudiantes y padres de familia), compensan el peso de las pruebas estandarizadas. Respecto a estas últimas, se le permite al docente seleccionar la especialidad en que preferían ser evaluados dentro de la prueba de saberes especializados, una de las cuatro que tienen que enfrentar. ${ }^{27}$ Esta metodología evaluativa ha producido resultado satisfactorios. ${ }^{28}$ Se valoran sin embargo como insuficientes respecto a la demanda, las posibilidades de formación continua y capacitación gratuitas, a pesar de haber sido potenciadas por la creación del sistema SIPROFE, la Universidad Nacional de Educación (UNAE) y convenios con IES internacionales. ${ }^{29}$

\subsection{Innovaciones de la reforma ecuatoriana en la regulación de la enseñanza privada}

Como es evidente, también en el caso ecuatoriano las pretensiones de rectoría se concentraban en el sistema educativo público. No obstante, aumentaron de forma significativa las atribuciones estatales respecto a la enseñanza privada. En cuanto a la regulación específica del trabajo de sus docentes, con la reforma éstos quedaron sujetos igualmente

$25 \quad$ Considérese que para la primera categoría de ingreso (Categoría J en el escalafón inicial de 2011) se estableció un sueldo mensual de 500 dólares, esto es, un 140 \% mayor que los 208 dólares que percibían con anterioridad. Posteriormente, si bien la evaluación de desempeño se generalizó para todos los ascensos, las mejoras salariales asociadas a cada categoría actuaron como poderosos incentivos. Por ejemplo para la primera categoría de ascenso (la H) se fijó un salario de 695 dólares. Además, los resultados obtenidos en la evaluación - por el docente y/o la institución de adscripción-serían considerados como uno de los componentes para la determinación de los salarios y se denominó «remuneración variable por eficiencia» (Art. 116). Otro aspecto importante de la LOEI fue homologar el sueldo de los docentes con los del resto de los servidores públicos regidos por la LOSEP, a partir de lo cual los maestros se beneficiarían automáticamente de los aumentos salariales para el sector público.

26 Según estadísticas de la prueba SER Maestro Recategorización publicadas por el INEVAL en su web institucional, en la convocatoria 2014-2015 participaron más de 65 mil docentes, lo que equivale a un $44 \%$ de los maestros que trabajan en las escuelas fiscales.

27 Cfr. Resolución 026 de 2016 del INEVAL

28 Según reportes de INEVAL sobre la prueba SER Maestro 2016 -evaluación de desempeño docente- aprobaron un 93,2 \% de los maestros evaluados.

29 Según un informe de la Subsecretaría de Desarrollo Profesional Educativo (2015), de 2008 a 2012 el programa SIPROFE atendió como promedio - anual- al 38 \% de la planta docente total. 
a la evaluación de desempeño (Art. 126). Según se documenta en los informes del INEVAL relativos a la prueba «Ser Profesor» en 2015, tales evaluaciones se han aplicado de forma efectiva aunque sólo a centenar y medio de docentes. Aunque no era posible para la legislación educativa ordenar un vínculo directo entre los resultados obtenidos en estas evaluaciones y la remuneración salarial, la LOEI estableció que no debían ser menores que el salario básico unificado (Art. 127), el cual ha aumentado en un $104 \%$ aproximadamente (de 2006 a 2016), situándose en los 366 dólares. Para aumentar el peso de esta disposición, en las últimas reformas a la LOEI en 2015 se determinó que la autoridad educativa garantizaría que los maestros privados además percibieran las prestaciones correspondientes, y añadió que en caso de incumplimiento las autoridades educativas podrían «sancionar a los responsables». Otra brecha abierta para que el Estado interviniese en la fijación de las retribuciones salariales de los maestros privados, se promueve en el Reglamento General de la LOEI, cuando enuncia que «las remuneraciones de los docentes y directivos serán proporcionales a su antigüedad, experiencia, eficiencia, funciones y responsabilidades» (Art. 136), estándar que se infiere será revisado al ubicar a las escuelas en los rangos para el cobro de pensiones y matrículas que establezca el MINEDUC. El cumplimiento de tales disposiciones, se ve reforzada por el salto cualitativo que ha experimentado la supervisión escolar, en tanto el MINEDUC ha implementado inspecciones aleatorias - ya no motivadas por quejas-y nuevas instancias para la denuncia inmediata de irregularidades por los ciudadanos, estándares que -en contraste- México había incorporado antes. La profesionalización de los empleados del sector público también ha tributado a supervisiones más efectivas. Un último aspecto relacionado con la evaluación de los profesores privados, es que en principio la LOEI les permite acceder a las opciones de formación continuas del SIPROFE. En la práctica, al menos hasta diciembre de 2016 esta opción continuaba limitada a los docentes de escuelas públicas.

En lo ateniente a jornada laboral, cabe añadir que el Reglamento General precisó que si bien ésta debía adecuarse a lo prescrito en el Código de Trabajo, de igual modo respetaría la distribución de tiempos para la labor educativa fuera de clases pautada para los docentes públicos (Art. 40). No obstante, en el problema neurálgico de estimular la contratación a tiempo completo, la legislación no avanza ningún incentivo, manteniendo así el estado de sub-regulación previa. A modo de balance, aun cuando la nueva ley educativa tenía límites claros en su capacidad de alterar el ordenamiento laboral de los maestros privados, este ámbito no se mantiene inmune a los ánimos de rectoría de la norma. Así, se trazan pautas explícitas que en principio obligan a la administración de estos centros, y los sujetan a supervisión.

De forma general, la reforma educativa ecuatoriana expresa tendencias similares a las apuntadas mediante el concepto de refuncionalización para México. En el país andino, se observa con claridad la presencia de un intervencionismo que apela a medidas semejantes e incluso avanza más allá. Lo anterior no es óbice para que al menos en el plano de la estabilidad laboral se observe una particular desregulación espoleada por la pugna sostenida con el sindicato magisterial más importante del país. En todo caso, el sentido político de los cambios educativos se demuestra atravesado por vectores diversos. Si por una parte, se observa la intención de debilitar a la UNE, las claras medidas en pro de las condiciones laborales de los docentes - tales como la retribución salarial y opciones de formación - favorecen la construcción de nuevas alianzas por el gobierno. Por su parte, la mayor regulación del sector privado no se plantea como una guerra abierta 
a sus gestores, sino más bien como un modo de afianzar los derechos de sus usuarios y de apuntalar mejoras para su personal educativo. Por esta vía, se pretende de igual modo incrementar la legitimidad social del gobierno. En este último aspecto, es interesante observar que el Estado ecuatoriano procura superar una inveterada sub-regulación del importante sector privado y mixto, empeño en el cual debe incorporar estándares ya alcanzados desde mucho antes por países como México, pero también sobrepasarlo mediante mecanismos indirectos de regulación salarial.

\section{Comentarios finales}

Hasta este punto, la revisión de los casos estudiados devuelve argumentos suficientes para concluir que el estudio de las funciones del Estado respecto a la educación no ha dejado de ser un semillero fructífero para la investigación especializada. Tanto la experiencia de México como Ecuador en las nuevas regulaciones del trabajo docente, denotan que no hay un retraimiento estatal, sino más bien una efectiva refuncionalización, en la que alternan proyecciones intervencionistas (clásicas y novedosas) con la desregulación e inclusive subregulación. Resaltamos entre estas tendencias, la emergencia de una nueva variante de intervencionismo. Este redunda en un mayor control del Estado sobre el servicio docente y el impulso a su profesionalización, a través de la instauración de concursos de méritos organizados por entes con competencia técnica y diferentes dosis de autonomía. Aunque el centro del nuevo intervencionismo estatal atañe al sector público, el espíritu de las reformas alcanza a la enseñanza privada, que no obstante sigue siendo un ámbito expuesto a una importante subregulación.

Pero no todo son semejanzas en las reformas analizadas, siendo sus diferencias un espacio oportuno para la retroalimentación. Por ejemplo, los modos en que la reforma mexicana regula la autonomía del ente evaluador pueden ser de aportación para su homólogo en el país andino. Por su parte, la preponderancia de los incentivos positivos y la complejidad de las metodologías evaluativas de Ecuador ofrece un referente práctico para México.

Es importante remarcar que en ambos países las reformas han desplazado el papel desempeñado hasta entonces por las organizaciones sindicales y debido a ello enfrentan su resistencia. Este filo anti-sindical de las reformas, amenaza con derivar hacia problemas de desregulación y no ha estimulado un enfoque más garantista de la legislación laboral. A pesar de ello, es un hecho que tanto en México como en Ecuador las reformas han logrado avanzar, bien por el amplio descrédito de las cúpulas sindicales, por la determinación estatal de impulsarla, o por el respaldo que suscitan ciertas mejoras en las bases docentes. No obstante, las próximas coyunturas electorales en ambos países traen incertidumbre sobre el desarrollo de las reformas, por lo cual se prefiere denominarlas como «apuestas», y no como realidades ya cristalizadas.

Por último, suponiendo lo no reversibilidad de las reformas, quedan numerosos desafíos pendientes para ambos países. Entre los más acuciantes se encuentran los de subordinar la evaluación al fortalecimiento de la formación (inicial y continua) al alcance de los maestros, así como a la optimización de modelos educativos que orienten su trabajo. La progresiva conciliación de evaluaciones recurrentes y estabilidad laboral es otro imperativo insoslayable. Asimismo, reclama mayor atención cómo fomentar el trabajo colectivo de los maestros, o cómo habilitar instancias efectivas de incidencia en las distintas fases de la política educativa. En un horizonte más amplio, el cometido estatal de mejorar la calidad educativa reclama atender otros factores que también afectan el aprendizaje de los estudiantes, especialmente las enormes desigualdades de contextos (económicos-sociales-culturales). 


\section{Referencias bibliográficas}

ALCALDE JUSTINIANI, A. (2014): Reflexiones sobre el contenido laboral de la reforma educativa, in DEL CASTILLO, G. \& VALENTI, G. (eds.) Reforma educativa ¿qué estamos transformando? Debate informado, pp. 114-121 (México, FLACSO).

ARNAUT, A. (2010): Gestión del sistema educativo federalizado 1992-2010., en ARNAUT, A. \& GIORGULI, S. (eds.) Los grandes problemas de México. Educación, pp. 233267 (México, COLMEX).

BENSUSÁN, G. \& TAPIA, L. A. (2014): Los problemas de implementación de la reforma educativa, en: DEL CASTILLO, G. \& VALENTI, G. (eds.) Reforma educativa ¿qqué estamos transformando? Debate informado, pp.98-112 (México, FLACSO).

BANCO MUNDIAL (1996): Prioridades y estrategias para la educación (Washington D.C, BM).

CEPAL/UNESCO (1992): Educación y conocimiento: eje de la transformación productiva con equidad (Santiago de Chile, CEPAL).

DALE, R. (2007): Los efectos de la globalización en la política nacional: un análisis de los mecanismos, en BONAL, X., TARABINI, A. \& VERGER, A. (eds.) Globalización y Educación. Textos fundamentales, pp. 87-114 (Buenos Aires, Miño y Dávila).

DE IBARROLA, M. (2014): El conocimiento profesional docente, en el marco de la reforma educativa, en DEL CASTILLO, G. \& VALENTI, G. (eds.) Reforma Educativa ?qué estamos transformando?: debate informado, pp. 74-97 (México, FLACSO).

DEL VALLE, S. (2015): Acaba imperio de la SNTE: sólo tiene tres Secretarías (http:// diario.mx/Nacional/2015-10-18_dffed8b9/acaba-imperio-de-snte-tiene-solotres-secretarias/) [Consultado el 11 de noviembre de 2016].

DIGITAL, P. (2011): Maestros que abandonen las aulas serán sancionados, PP Digital, 5 de octubre de 2011.

FELDFEBER, M. (2007): La regulación de la formación y el trabajo docente: un análisis crítico de la agenda educativa en América Latina, Revista Educ. Soc., 99, pp. 444465 .

FERNÁNDEZ-MARTÍNEZ, M.A. (2012): From the Streets to the Classroom: the politics of education spending in Mexico, Tesis doctoral, (Duke University).

FERNÁNDEZ-MARTÍNEZ, M.A (2014): Los desafíos de la implementación de la reforma educativa y la perspectiva estatal (http://imco.org.mx/indices/documentos/ ICE2014_Capitulos/2014_ICE_Educativa.pdf) consultado el 20 de mayo de 2016.

FUENTES MUÑIZ, M. (2013): Reforma educativa lesiona derechos básicos «hay materia para amparo», en POY LOZANO, L., La Jornada, 10 de febrero de 2013.

GUEVARA NIEBLA, G. (2016): Sobre el servicio profesional docente, Nexos (http:// www.nexos.com.mx/?p=27761), consultado el 5 de mayo de 2016. 
HERNÁNDEZ, J. M., LLAMAS, I. \& GARRO, N. (2012): El mercado de trabajo de los trabajadores de la educación, en DE LA GARZA TOLEDO, E. (ed.) La situación del trabajo en México, 2012, el trabajo en crisis, pp. 313-344 (México, Plaza y Valdés):

HERNÁNDEZ, L. (2015): Despido a quienes no acudan a la evaluación: Nuño, Excelsior, 15 de octubre de 2015 .

LA REPÚBLICA (2011): UNE marcha para rechazar aumento horas de trabajo, La República, 5 de octubre de 2011.

MARTÍN-CRIADO, E. (2013): Sociología de la educación y compromiso político: el concepto de campo, Praxis Sociológica, 17, pp. 89-106.

MARÍN HERNÁNDEZ, G. (2015 ${ }^{\mathrm{a}}$ ): La Suprema Corte lee la Reforma Educativa I/ II. Nexos (http://eljuegodelacorte.nexos.com.mx/?p=5051\#_ftnref11) consultado el 11 de noviembre de 2016.

MARÍN HERNÁNDEZ, G. (2015b): La suprema corte lee la Reforma Educativa II/ II. Nexos (http://eljuegodelacorte.nexos.com.mx/?author_name=gustavo-marinhernandez) consultado el 11 de noviembre de 2016.

MERCADO, A. \& BRITO, O. (2016): Legisladores de izquierda y CNTE crean frente contra reforma educativa, Milenio.com, 11 de julio de 2016.

MERCADO-PACHECO, P. (2005): Estado y globalización ¿crisis o redefinición del espacio político estatal? (https://www.uam.es/otros/afduam/pdf/9/127_150 \%20 pedro \%20mercado.pdf), consultado el 30 de marzo de 2016.

OECD (1991): Escuelas y calidad de la enseñanza. Informe Internacional (Buenos AiresMéxico D.F., Ministerio de Educación y Ciencia).

ORNELAS, C. (2008): Política, poder y pupitres: crítica al nuevo federalismo educativo (México, Siglo XXI).

ORNELAS, C. (2012): Educación, colonización y Rebeldía: la herencia del pacto Calderón-Gordillo (México, Siglo XXI).

PAOLI BOLIO, F. J. (2013): Elementos relevantes de la reforma educativa, en RAMÍREZ RAYMUNDO, R. (ed.) La reforma constitucional en materia educativa: alcances y desafíos, pp. 169-177 (México: Instituto Belisario Domínguez).

POY SOLANO, L (2016): La evaluación, viacrucis, dicen maestros a Nuño, La Jornada, 4 de marzo de 2016 .

RAMÍREZ RAYMUNDO, R. (2013): La reforma constitucional en materia educativa cuna nueva estrategia para mejorar la educación Básica? en RAMÍREZ RAYMUNDO, R. (ed.) La reforma constitucional en materia educativa: alcances y desafíos, pp. 123-139 (México: Instituto Belisario Domínguez).

REIMERS, F. (2000): ¿Equidad en la educación?, Revista Iberoamericana de Educación, 23 (http://rieoei.org/rie23a01.htm) consultado el 5 de diciembre de 2016.

ROSAS, T. (2016): Contrarreforma educativa como iniciativa ciudadana, El Economista, 
24 de agosto de 2016.

SÁNCHEZ PÉREZ, H. (2004): La formación inicial de los maestros de educación primaria: un análisis comparativo de las propuestas de formación docente en Argentina, Costa Rica, Chile y México, Tesis de Maestría (Universidad Iberoamericana).

SCHMELKES, S. (2014): La evaluación como derecho. Sylvia Schmelkes y Manuel Gil, una conversación (http://www.educacionfutura.org/la-evaluacion-como-derechosylvia-schmelkes-y-manuel-gil-una-conversacion/) consultado el 27 de octubre de 2016.

SEP (2016): Comunicado 75 No tendrán liquidación 3 mil 360 maestros separados del servicio por no presentar Evaluación del Desempeño.

SOSA ELIZÁGA, R. (2012): Hacia la recuperación de la soberanía educativa en América Latina: conciencia crítica y programa (México, UNAM).

SUBSECRETARÍA DE DESARROLLO PROFESIONAL EDUCATIVO (2015): Proyecto Sistema Integral de Desarrollo Profesional Educativo (SíProfe) Año 2010 - 2015, (Quito, MINEDUC).

TENTI FANFANI, E. (2004): Algunas dimensiones de la profesionalización de los docentes. Representaciones y temas de la agenda política, Revista PRELAC (http:// unesdoc.unesco.org/images/o013/o01372/137293s.pdf\#137357) consultado el o6 de noviembre de 2016.

TIRAMONTI, G. (2001): Sindicalismo docente y reforma educativa en la América Latina de los 90. PREAL, 19 (http://www.ub.edu/obipd/docs/sindicalismo_docente_ tiramontig.pdf) consultado el 19-11-2016. 